\title{
Market Deregulation and Insurer Pricing Strategies: The Japanese Experience
}

\author{
Nat Pope ${ }^{\mathrm{a}}$ and Yu-Luen $\mathrm{Ma}^{\mathrm{b}}$ \\ ${ }^{a}$ Bradley University, USA. E-mail: npope@bradley.edu \\ ${ }^{\mathrm{b}}$ Illinois State University, IL, USA
}

In 1998, rate regulation in the Japanese auto insurance industry shifted from a tightly controlled tariff regime to that of a less regulated (theoretically) prior approval system. While actual rate regulation is generally not directly observable, Danzon (1983) contends that the "true" character of regulation is indirectly observable in the pricing strategies of insurers. This paper applies Danzon's hypothesis to the Japanese auto insurance market. The empirical analysis employs a two-way random-effects panel data methodology that includes data from the domestic competitors in the Japanese auto insurance market over the 1991-2000 period. Even though an increased dispersion of pricing strategies corresponding to insurer size is observed after deregulation, our analysis reveals that the Japanese auto insurance market still operates much like a cartel. The implication is that despite formal deregulation, Japan's regulatory body still maintains significant control.

The Geneva Papers (2005) 30, 312-326. doi:10.1057/palgrave.gpp.2510028

Keywords: Japan; insurance; deregulation; regulation; price; Danzon

\section{Introduction}

The impact of rate regulation on insurer pricing behaviour has received significant attention in the literature over the past few decades. However, a consensus as to the nature of the relationship shared by the regulation of an insurance market and its market price level has been difficult to reach. Does insurance regulation encourage price competition or, alternatively, does it facilitate collusive pricing behaviour among market competitors? Given the central role it plays in the world economy, the U.S. market has been the traditional focus of much of the earlier research on this topic. It is our position, however, that the U.S. market represents a uniquely onerous market on which to perform such analyses, which contributes to the lack of a clear understanding of the shared relationship between a market's regulatory environment and insurer pricing behaviour in that market.

In a review of the literature focused on the U.S. market, two problematic modelling issues surface repeatedly. The first issue relates to impediments associated with data aggregation standards. Given the state level control over insurance market regulation, any analysis of the U.S. market related to regulation must occur at the state level. Such analyses require, at a minimum, insurer price data on a state-by-state basis. While loss and premium data are readily available at the state level, associated data for nonprice control variables are only available at the national level. While the importance of 
controlling for nonprice competition has been acknowledged in the literature, ${ }^{1}$ as of this writing, no U.S.-based studies have been able to control for these effects. The second modelling challenge relates to the frequent use of a binary classification system in controlling for the effects of a state's regulatory environment. Earlier research focused on the U.S. market has typically employed cross-sectional modelling structures that compare insurers' pricing behaviour across state markets. When controlling for market regulatory structure, these studies have typically classified the market as being either openly competitive or prior approval, or more generically, competitive or noncompetitive. ${ }^{2}$ This coarse classification system, however, lacks the ability to assess accurately the true nature of regulation within a given market. ${ }^{3}$ Some researchers have argued that a more appropriate method of regulatory system classification would be based on the stringency with which regulatory standards are actually enforced. ${ }^{4}$ Nonetheless, the simplified binary classification system continues to be employed in most investigations focusing on the U.S. insurance industry. ${ }^{5}$

To overcome the challenges noted above, this research investigates the relationship shared by the regulatory environment and insurer pricing behaviour by shifting the analysis to the Japanese auto insurance market. ${ }^{6}$ The Japanese market converted from a tariff market to a prior approval system in 1998, which allows for an assessment of changes in insurer pricing behaviour under differing regulatory regimes. ${ }^{7}$ This singlemarket focus escapes the need for a potentially flawed classification of regulatory systems across state markets. Both price and nonprice firm-level data are also available on a comparable basis due to the lack of state-by-state regulatory fragmentation, as found in the U.S. Additionally, we examine the applicability of

${ }^{1}$ See, for example, Saba (1978); Samprone (1979); Ippolito (1979); Harrington (1984).

${ }^{2}$ For example, Samprone (1979) notes that, "for the sake of simplicity," he classifies state regulatory markets into two categories, openly competitive and prior approval systems. The prior approval systems include 36 states operating under five different systems: states having state made rates (2), mandatory bureau rates (1), true prior approval systems (26), modified prior approval systems (2) and file and use systems (5). In reality, any of the above systems might more accurately reflect the regulatory environment of an openly competitive system if regulatory standards were enforced in a relatively loose manner.

${ }^{3}$ Tennyson (1997); Eastman and Maroney (2000).

${ }^{4}$ Muir (1968); Hartman (1970); Schader (1982); Nadel (1982); Mintel (1983); Harrington (1984); Tennyson (1997).

5 A notable exception is Tennyson (1997) who adopted Conning and Company's (1992) survey data as the proxy for market regulatory environment. Conning and Company surveyed U.S. insurance executives and regulators in an attempt to more succinctly assess the true nature of regulation within given state markets, irrespective of the formal regulatory classification system. While these results may offer a more sensitive assessment of a state's true regulatory environment, it suffers from traditional difficulties associated with survey data, for example, subjectivity, potentially flawed queries, etc.

${ }^{6}$ Auto insurance markets are commonly employed in insurance pricing analyses because of its broad availability, relative homogeneity of product structure, and dominance as a line of insurance.

${ }^{7}$ Under the tariff market regime, auto insurers were required to use reference rates provided by the Automobile Insurance Rating Organization (AIRO) (now part of the Non-Life Insurance Rating Organization [NLIRO] of Japan). Reference rates are based on estimates of loss costs (as opposed to expense costs). Similarly, form deviation was not permitted and allowable-underwriting criteria were limited to three characteristics: the vehicle-type, its usage, and whether any young persons were included on the policy. All of these restrictions were significantly, in theory, relaxed under the current prior approval system. Additional details are available at the NLIRO website (http://www.nliro.or.jp/). 
Danzon's (1983) theorized relationship between competitor pricing strategies as a reflection of the true nature of regulation in a marketplace (discussed in more detail later in the paper). With this additional level of analytic refinement, this study not only analyzes the relationship shared by a market's regulatory environment and insurer pricing behaviour, but also assesses the "true" nature of regulation within that market, according to Danzon's framework.

This research contributes to the existing body of literature in two primary ways. The first contribution relates to modelling and methodological improvements. The ability to control for nonprice competition and eliminate the need for potentially flawed classification of regulatory systems allows for greater confidence in the empirical outcomes. The second contribution relates to a clearer understanding of the Japanese insurance marketplace. This includes an assessment of changes in insurer pricing strategies, subsequent to deregulation. The findings associated with this research will be of interest to not only insurers currently operating in that marketplace, but also to foreign competitors who are contemplating entry into that increasingly accessible market. Given the global trend toward deregulation of national insurance markets, for example, China, India, and the European Union, those seeking a better understanding of the effect of regulatory changes on firm-level pricing behaviour, for example, policy makers and regulators, will have a keen interest in these findings.

In the following section, the literature review is presented and a deeper understanding of the Japanese auto insurance market is developed. Subsequently, model development and variable discussion follow, which lead to a discussion of the empirical results and a summary of the pertinent findings.

\section{Literature review}

The mélange of research devoted to the relationship shared by regulatory environment and market-pricing levels is difficult to summarize concisely due to the variety of methodological approaches and varying data sets employed. However, in his survey of then-current pertinent literature, Harrington (1984) provides a rationale for the organization of the body of research. Some analyses have found evidence of relatively higher price levels in regulated markets, that is, support for the excessive price hypothesis. ${ }^{8}$ Other studies have found price levels in regulated markets to be lower than would be found in an otherwise competitive marketplace, that is, support for the rate suppression hypothesis. ${ }^{9}$ Still other research has found no long-term effect on price levels - reflective of the regulatory lag hypothesis. ${ }^{10}$ Harrington also identifies a handful of studies focused on alternative theories such as the capture theory of regulation. ${ }^{11}$ While a clear consensus as to the regulatory-price level relationship

\footnotetext{
${ }^{8}$ See, for example, Joskow (1973); Saba (1978); Samprone (1979); Ippolito (1979); Frech and Samprone (1980); Finsinger and Schmid (1994).

${ }^{9}$ See, for example, Muir (1968); Ancipink (1980); Cummins et al. (2001).

${ }^{10}$ See, for example, Hanson et al. (1974); New York Insurance Department (1975); General Accounting Office (GAO) (1979).

${ }^{11}$ See, for example, Stigler (1971); Peltzman (1976).
} 
remains somewhat elusive, support for the rate suppression hypothesis appears to have garnered general support in the broader body of literature. ${ }^{12}$

The vast majority of the pertinent literature focused on the U.S. market has approached the empirical analysis of the relationship between regulation and market price level by employing multi-state panel data methodologies where regulatory variables were time invariant. A less extensive body of literature has focused on behavioural changes in single-state markets that have deregulated. ${ }^{13} \mathrm{~A}$ fundamental difference between those studies and the Japanese experience is that those state-based studies have traditionally examined regulatory shifts from prior approval systems (or some variant of a moderately regulated system) to openly competitive markets. This is contrasted with Japan, which shifted from a tariff market to a prior approval system. Thus, application of the findings of the U.S.-based studies to the Japanese experience must be tempered with the knowledge that the changes in regulatory environments are not necessarily comparable. One national market study that bears some semblance to this current analysis of Japan is Barros' (1996) analysis of the Portuguese auto insurance market. Barros compared firm-level behaviour (controlling for operational costs, prices, and insurer-size) across a shift in regulatory environments (from a tariff market to a less regulated system of price announcements) in testing for increases in competitive marketplace behaviour. He found that the new regulatory system did indeed share a relationship with increased price competition.

The Japanese market also possesses a number of other simplifying characteristics that mitigate the need for excessive control for externalities. Some of the more salient characteristics include high barriers to entry, market stability, limited number of competitors, and similar business strategies among insurers. ${ }^{14}$ Notable is that insurersize has been found to be a significantly differentiating characteristic among Japanese insurers with respect to both expense and loss ratios. ${ }^{15}$ Thus, Danzon's (1983) work that theorizes dissimilar pricing strategies for insurers of different sizes may hold special significance in this market. Danzon coalesces what was previously only a loose body of associated intuition into a concise set of hypotheses regarding the behaviour of regulators and market competitors. She envisions two possible roles for regulation, one encouraging a cartel-like environment and a second where regulation is less intrusive and promotes itself as a supporting service for industry participants. The cartel model reflects an environment where bureau rates are set relatively high and the regulatory body encourages adherence those rates. In that environment, market leaders, that is, larger insurers, gladly comply and enjoy associated high profitability. Small insurers, on the other hand, will attempt to undercut the bureau rate (and the rates of their larger competitors) in attempting to capture increased market share. Alternatively, the service model envisions a less intrusive regulatory involvement - a market that allows for greater pricing freedom. In this market, small insurers, with their correspondingly shallower pools of proprietary data, will rely more heavily on

\footnotetext{
${ }^{12}$ Cummins et al. (2001); Tennyson (1997).

${ }^{13}$ See, for example, New York Insurance Department (1975); Grace et al. (1998); Jaffee and Russell (1998).

${ }^{14}$ For further discussion of the nature of the Japanese nonlife market, see Kwon and Skipper (1997); Ostrom (1998); Moody's Investor Services (1998, 1999, 2001); Hayakawa et al. (2000).

${ }^{15}$ Pope (2004)
} 
supplied-bureau rates in setting their price. Large insurers, however, with deeper pools of data, will set rates that are more reflective of their own experience. Thus, large insurers will be more likely to deviate from bureau rates, either in a positive or negative direction. Characteristics of cartel and service models are summarized in Table 1.

This framework for analysis of the Japanese market provides a number of benefits. First, its conceptual focus on insurer-size as a differentiating characteristic has special significance in that marketplace. Additionally, there is no reliance on possibly flawed or inadequate descriptions of the market's regulatory philosophy in the empirical analysis. Noting the timing of the shift from a tariff market to a prior approval system is sufficient - no qualitative assessment as to the true nature of the prior approval system is necessary. Indeed, specifying the true nature of regulation after the shift in regime is the purpose of the application of Danzon's framework.

Danzon's (1983) empirical analysis of the U.S. market found general support for the service model hypothesis. Given the relatively competitive regulatory philosophies employed by most state markets, this finding is not overly surprising. The structure of the Japanese market, however, differs significantly from the U.S. Many Japanese market characteristics mirror those commonly found in collusive markets, for example, small number of competitors, concentrated market share, high barriers to entry, homogeneous product, etc. ${ }^{16}$ Additionally, the Japanese insurance marketplace did not universally welcome the arrival of rate deregulation in $1998 .{ }^{17}$ Aside from resentment associated with perceived foreign meddling, some insurers suggested that they were not yet capable of operating successfully without strong regulatory guidance. Some insurers even suggested they would refuse to compete on price after deregulation took place. ${ }^{18}$ There was also doubt as to the degree to which regulators would allow the spirit of a prior approval system to operate. Nanto (1995) suggests that the most direct beneficiaries of strict regulation are Japan's bureaucrats themselves because it ensures their continued central role in the process and that they would only reluctantly relinquish this control - reminiscent of the capture theory of regulation.

Subsequent to deregulation, media reports have provided contradictory evidence as to marketplace behaviour. The Nikkei Weekly (2001) reported that insurers largely refused to compete openly on price and instead chose to expand policy benefits without increasing rates proportionally (within the insurance context, this strategy is analogous to price competition). ${ }^{19}$ Still others reported that key insurers who held potential competitive advantages appeared to resist any form of open competition. ${ }^{20}$

\footnotetext{
${ }^{16}$ See Stigler (1971) for a deeper theoretical discussion of these characteristics.

17 Japan Non-Life Insurance Newsletter (1997).

${ }^{18}$ Ostrom (1998); Moody's Investor Services (1998).

${ }^{19}$ Conceptualizing the insurance transaction to be the acceptance of a unit of risk for a given cost (rate), an increase in benefits, for example, broadened coverages, liberalized underwriting and claims settlement, etc., represents a product enhancement. These expanded benefits are reflected in increased loss costs. Thus, while rates may technically not increase, the additional service provided has resulting in a lower per unit cost of insurance coverage, that is, price reduction.

${ }^{20}$ Moody's Investor Services (2001).
} 
Table 1 Summary of model hypotheses

\begin{tabular}{|c|c|}
\hline Cartel model & Service model \\
\hline $\begin{array}{l}\text { Large firms less likely to deviate from bureau rates } \\
\text { than small firms }\end{array}$ & Small firms are more likely to adhere to bureau rates \\
\hline $\begin{array}{l}\text { Any deviations from the bureau rate will be in a } \\
\text { downward direction }\end{array}$ & $\begin{array}{l}\text { Deviations from bureau rates by large firms may be } \\
\text { either upward or downward }\end{array}$ \\
\hline $\begin{array}{l}\text { A "significant" share of the market must adhere to } \\
\text { bureau rates to convey market power }\end{array}$ & $\begin{array}{l}\text { It is not necessary that a "significant" share of the } \\
\text { market adheres to bureau rates - the service } \\
\text { provided ensures its continued survival }\end{array}$ \\
\hline $\begin{array}{l}\text { Regulators will seek to enforce bureau rates, that is, } \\
\text { stringent regulation }\end{array}$ & $\begin{array}{l}\text { Regulators will not seek to enforce bureau rates, that } \\
\text { is, weak regulation }\end{array}$ \\
\hline
\end{tabular}

Other qualitative research describing the nature of regulation under both regimes provides little evidence that much has changed - a producer-protection motivation still exists for regulators. ${ }^{21} \mathrm{~A}$ coarse comparison of auto insurance industry average loss and expense ratios across the pre- and post-deregulation periods suggests that little has changed (62.2 to 62.7 per cent and 33.8 to 33.2 per cent, respectively). Thus, the reality of insurer pricing behaviour subsequent to deregulation remains obscure.

This research employs Danzon's framework in investigating the market pricing response to the regulatory shift in Japan. While the analysis will shed light on a number of issues, the two core questions this analysis attempts to answer are:

- Has a shift to a less regulated environment affected insurer pricing strategies?

- Does either of Danzon's models of theorized pricing behaviour accurately reflect firm pricing strategies in the post-deregulation period in Japan?

\section{Data and variable discussion}

\section{Dependent variable}

Danzon's hypotheses predict specific relationship between an insurer's willingness to deviate from bureau rates and the insurer's size. When given the freedom to do so, the cartel model predicts small insurers will display significantly lower rates, relative to the rest of the market, while the rates of large insurers will more closely approximate bureau rates. Conversely, the service model predicts rate dispersion at either extreme, only by large insurers. Lacking sufficient depth in their pools of data, small insurers are expected to rely more heavily on bureau rates. Therefore, this investigation develops two parallel analyses, each testing for one of Danzon's hypothesized models. The dependent variable for the cartel model is the degree to which an insurer's rate deviates from the bureau rate and can be expressed as

$$
D_{E V I A T I O N}{ }_{i, t}=R A T E_{i, t}-B U R E A U R A T E_{t},
$$

where $i$ identifies the insurer $(i=1,2,3, \ldots, n)$ and $t$ identifies the year $(t=1991,1992, \ldots, 2000)$. Insurer rates $(R A T E)$ are proxied by the inverse-of-loss

\footnotetext{
${ }^{21}$ Kwon and Skipper (1997); Hayakawa et al. (2000).
} 
ratio, ${ }^{22}$ the commonly used proxy for insurer prices. $^{23}$ A concise proxy for bureau rates proves more elusive - such data are not publicly available in Japan. Given the lack of available data, the Non-Life Insurance Rating Organization (NLIRO) of Japan, ${ }^{24}$ which establishes bureau rates, suggests that the average rate for all auto insurers in the immediately preceding year $(t-1)$ provides a feasible proxy for the bureau rate in the subsequent period: ${ }^{25}$

$$
B U R E A U R A T E_{t}=\frac{\sum_{i=1}^{n} R A T E_{i, t-1}}{n} .
$$

The heavy reliance on retrospective bureau rates in setting current rates is common in tightly regulated markets such as Japan. ${ }^{26}$ Danzon's service model predicts insurer rate deviation from bureau rates in either direction. Thus, the dependent variable for the service model will be the absolute value of dependent variable $(|D E V I A T I O N|)$ employed in the cartel model.

\section{Independent variables}

The relationship between firm-size and pricing behaviour in deregulated markets is at the heart of this analysis. Due to tight rate-regulation under the tariff regime, a dispersion of pricing strategies among insurers is not anticipated in the Japanese marketplace prior to deregulation. However, in a less regulated environment Danzon anticipates the pricing strategies of small and large insurers to diverge and in the process reveal the true nature of regulation in that market. To control for differences in firm size, a binary variable is included that separates Japanese domestic auto insurers into one of two pools based on total book-of-business net premium market share. Insurers consistently controlling over five per cent market share are identified as large firms ( $L A R G E)$ while all others are considered small. While this point of delineation is subjective, the choice is not without its rationale. When insurers are sorted and ranked according to market share, there is a consistent and natural separation between two clusters of insurers at the five per cent market share level. This

${ }^{22}$ The inverse-of-loss ratio in this analysis is calculated by dividing net written premiums by losses (including loss adjustment expenses). Earned premiums, a more appropriate choice for the numerator in this calculation, are not available from Japanese data sources and thus, net written premiums are employed as an alternative. The inverse-of-loss ratio is sometimes referred to as the "unit price" of insurance (Cummins et al., 2001). The terms insurance "price" and "rate" are used interchangeably within the context of this paper.

${ }^{23}$ See, for example, Tennyson (1997); Cummins et al. (2001).

24 Source: Mr. Yoshihiko Suzawa, Deputy Manager, NLIRO.

${ }^{25}$ Tariff regime requirements mandated that insurer rates fall within \pm 10 per cent of the published bureau rates. Employing these proxies for bureau rate and insurer rates, the required standard was met 92.2 per cent of the time. The lack of 100 per cent compliance with those standards is not cause for concern. By definition, proxies lack perfect correlation with the variable of interest and thus, a 7.8 per cent level of noncompliance with rate requirements during the tariff market would be a reasonable possibility. Also of interest is that even after deregulation this \pm 10 per cent standard is still met 90.6 per cent of the time. The ability of bureau rates to demonstrate continued market power is anticipated by Danzon's cartel model (see Table 1).

${ }^{26}$ Swiss Re (2001). 
point of differentiation creates two similarly sized pools for large and small insurers, 90 and 112 observations, respectively. The large-insurer group, which consists of nine insurers, consistently controls about 79 per cent of the market. Membership in the small group, including anywhere from eight to 17 insurers, depending on the year, is less stable than the large-insurer pool in terms of the number of competitors.

The pre- and post-deregulation periods are identified by a dummy variable (DEREG) that takes the value of one (1) for the deregulated period. An interaction term $(D E R E G * L A R G E)$ is included to test for potential differences in pricing behaviour between large and small firms in the deregulated marketplace. Due to the nature of construction of this model, the coefficient for the DEREG variable reveals the behaviour of small insurers during the post-deregulation period. A negative relationship between DEVIATION and DEREG suggests that small insurers will increase their willingness to deviate negatively from bureau rates after deregulation, a relationship anticipated by Danzon's cartel model. Conversely, the willingness of large insurers to deviate from bureau rates is not expected to change after deregulation and thus, no statistically significant relationship is anticipated between DEVIATION and $D E R E G * L A R G E$. Danzon's service model, however, anticipates a positive relationship between $|D E V I A T I O N|$ and $D E R E G * L A R G E$, which suggests that large insurers are willing to deviate from bureau rates (in either direction). The service model does not expect a statistically significant relationship between $|D E V I A T I O N|$ and DEREG because smaller insurers are not expected to deviate from bureau rates even after deregulation.

As noted earlier, competition in the marketplace takes place on both price and nonprice factors and thus, control of those nonprice variables is appropriate. Within the underwriting context, general operating expenses and commissions represent the two major expenses categories associated with nonprice competition. These expenses typically represent almost 40 per cent of total production costs for the auto lines of business in Japan. ${ }^{27}$ As all costs of production are typically passed along to the consumer, it is anticipated that both general operating expenses and commissions will share a positive relationship with the dependent variable in this analysis. Both general operating expenses $(G O E)$ and commissions (COMMISSION) are standardized by net auto premiums. $^{28}$

The demand and supply of nonlife insurance products share contradictory relationships with price in an insurance marketplace. ${ }^{29}$ Together, however, they help establish a market price level. Given that supply and demand for insurance is reflected in the general health of the market's broader economy, this analysis includes the per capita real gross domestic product $(E C O N)$ to control for variations in the economy

\footnotetext{
${ }^{27}$ The inability of Japanese management to successfully deal with a relatively high fixed cost structure, reflected in the general operating expenses, has proved to be one of the more difficult challenges facing that market (Moody's Investor Services, 1998).

${ }^{28}$ While the body of economic theory predicts an endogenous relationship may exist between price and nonprice variables (see, for example, Stigler, 1968; Kreps and Scheinkman, 1983; Sonnenholzner and Wambach, 2004), statistical tests failed to support this hypothesis in this research. Therefore, nonprice variables were treated as exogenous for the purposes of this analysis.

${ }^{29}$ See, for example, Beenstock et al. (1988); Browne et al. (2000); Ma and Pope (2003).
} 
across time. The specific relationship ECON shares with the dependent variable is not hypothesized.

An inverse relationship between the marketplace return on investment and the price of insurance has been well established. ${ }^{30}$ Multiple rationales exist for this expected relationship. For example, during periods of high return on invested assets insurers are able to reduce product price because investment returns on unearned premiums and reserves supplement the rates charged. Additionally, cash-flow underwriting intuition suggests that during period of high returns in the marketplace insurers will lower their price in order to garner higher premium volumes to invest in the marketplace. The reported yield on the insurers' financial asset portfolio (YIELD) is included to control for the hypothesized relationship.

The insurers' auto lines book-of-business, as a percentage of total book-of-business, is also included as a control variable (SPECIALIZATION). Tennyson (1997) found line-specialization to be a competitive advantage in the U.S. auto lines market and Jeng and Lai (2005) similarly reported a positive relationship between linespecialization and operational efficiencies in the Japanese nonlife insurance industry. Additionally, Pope's (2004) analysis of the Japanese auto insurance market found a negative relationship between auto lines specialization and loss ratios, implying a potential positive relationship with DEVIATION in this analysis.

In 1996, six life insurers entered the auto insurance industry when the regulatory barriers preventing inter-insurance industry competition were removed. While their impact on the nonlife industry is minimal and their market share remains small, their unique origin and sudden appearance in the market warrant special control. ${ }^{31} \mathrm{~A}$ binary variable (LIFE) is included in the analysis to identify those competitors who are life insurance subsidiaries. The relationship between LIFE and the dependent variables is not hypothesized.

A rational description of the expected relationship between the control variables and the dependent variable in the service model $(|D E V I A T I O N|)$ is not meaningful due to the ambivalent nature of that variable. Nonetheless, those variables still serve as appropriate control variables within the framework of this analysis and thus, their inclusion in the service model is appropriate. Table 2 describes the summary statistics of the variables included in this research.

\section{Data}

To answer these research questions, this analysis investigates the auto insurance lines for licensed domestic Japanese insurance companies. ${ }^{32}$ The time-period under investigation spans 1991-2000. Our sample includes 202 insurer-year observations. All data, with the exception of the ECON variable that was obtained from the Bank of Japan, are obtained from various annual issues of The Statistics of Japanese Non-Life

\footnotetext{
${ }^{30}$ See, for example, Swiss Re (2001).

${ }^{31}$ These start-up operations display unusually high expense ratios relative to the rest of the established market competitors.

${ }^{32}$ Excluded from the analysis are two mutual insurers and insurers demonstrating statistically significant aberrant behaviour in any given year.
} 
Table 2 Summary statistics ${ }^{\mathrm{a}}$

\begin{tabular}{|c|c|c|c|c|}
\hline & Mean & Std. Dev. & Min. & Max. \\
\hline DEVIATION & -1.75 & 10.39 & -45.69 & 36.65 \\
\hline$|D E V I A T I O N|$ & 7.74 & 7.14 & 0.10 & 45.69 \\
\hline$D E R E G$ & 0.36 & 0.48 & 0.00 & 1.00 \\
\hline$L A R G E$ & 0.45 & 0.50 & 0.00 & 1.00 \\
\hline$G O E$ & 17.84 & 5.36 & 10.31 & 41.41 \\
\hline COMMISSION & 18.30 & 1.42 & 12.63 & 20.90 \\
\hline$E C O N$ & 40.07 & 1.42 & 38.14 & 42.17 \\
\hline$Y I E L D$ & 3.73 & 1.20 & 1.32 & 6.43 \\
\hline SPECIALIZATION & 51.80 & 8.23 & 22.45 & 70.97 \\
\hline$L I F E$ & 0.08 & 0.27 & 0.00 & 1.00 \\
\hline
\end{tabular}

${ }^{a}$ All variables are presented as percentages with the exception of $L A R G E, L I F E$, and DEREG, which are binary variables, and $E C O N$, which is presented in $¥ 100,000$.

Insurance Business, published by the Insurance Research Institute of Japan (Hoken Kenkyujo). All monetary values are reported in Japanese yen (in millions) and have been inflation-adjusted using 1995 as the base year.

\section{Model}

Given the time-series and cross-sectional data structure, this analysis adopts a panel data methodology. Two-way random-effects models are used because some independent variables are time-invariant for insurers. The empirical models can be expressed as:

$$
\begin{aligned}
& \text { DEVIATION }_{i, t} \text { or } \mid \text { DEVIATION } \\
& \quad=\beta_{1, t} \text { DEREG }_{t}+\beta_{2} \text { LARGE }_{i}+\beta_{3}\left(\text { DEREG }_{t} * \text { LARGE }_{i}\right) \\
& \quad+\beta_{4} \text { GOE }_{i, t}+\beta_{5} \text { COMMISSION }_{i, t}+\beta_{6} \text { ECON }_{t}+\beta_{7} \text { YIELD }_{i, t} \\
& \quad+\beta_{8} \text { SPECIALIZATION }_{i, t}+\beta_{9} \text { LIFE }_{i}+\alpha_{i}+\lambda_{t}+u_{i, t},
\end{aligned}
$$

where $\alpha_{i}$, and $\lambda_{t}$, are company- and time-specific disturbances, respectively, and $u_{i, t}$ represents the regression errors. To correct for serial correlation, we assume first-order autoregressive for the error structure ${ }^{33}$ where

$$
u_{i, t}=\rho u_{i, t-1}+e_{i, t}
$$

\footnotetext{
33 The likelihood ratio test suggests that a first-order autoregressive methodology is superior to other alternatives. See Greene (1997) for further discussion.
} 


\section{Empirical results}

Table 3 presents the empirical results of the analyses along with the hypothesized signs for the models. The $L A R G E$ variable in the cartel model (which serves to differentiate the pricing behaviour of large and small insurers prior to deregulation) was not significant. Thus, as one might expect in a tariff market, significant price differentiation even across insurers of different size was not a characteristic of the marketplace. After deregulation, the empirical results provide evidence that the new regulatory regime more closely reflects Danzon's cartel model. Specifically, the negative statistical significance of the DEREG variable in the cartel model suggests that small insurers significantly negatively deviated from bureau rates after deregulation (an increase of -5.627 per cent). The statistical significance of the $D E R E G * L A R G E$ variable suggests that large insurers also consistently increased the degree to which they negatively deviated from bureau rates after deregulation, albeit only to a minimal degree. ${ }^{34}$ These results are graphically depicted (to scale) in Figure 1 and strongly support Danzon's expectations for a cartel model. The fact that statistical evidence is found in support of a cartel model implies that the service model is not applicable to the current Japanese regulatory environment. Additionally, the lack of significance of the DEREG*LARGE variable in the service model reinforces the lack of its applicability to the Japanese marketplace. The statistical insignificance of the key variables in the service model is consistent with the findings in the cartel model, that is, the statistical results of the two models are not contradictory.

Other control variables in the cartel model indicate varying levels of significance. YIELD was negatively significant, which was consistent with expectations. The health of the economy $(E C O N)$ was found to have a significantly negative relationship with the dependent variable. Succinct implications cannot be drawn from this finding as the

Table 3 Empirical results

\begin{tabular}{|c|c|c|c|c|c|c|}
\hline \multirow[t]{2}{*}{ Variable } & \multicolumn{3}{|c|}{ Cartel model } & \multicolumn{3}{|c|}{ Service model } \\
\hline & Hypotheses & Coefficient & $\begin{array}{c}\text { Standard } \\
\text { Error }\end{array}$ & Hypotheses & Coefficient & $\begin{array}{c}\text { Standard } \\
\text { Error }\end{array}$ \\
\hline Intercept & & 168.770 & 48.635 & & -9.376 & 40.290 \\
\hline LARGE & No relationship & -1.738 & 3.897 & No relationship & -4.207 & 2.710 \\
\hline DEREG & - & $-5.627 * * *$ & 2.134 & No relationship & 2.010 & 2.565 \\
\hline DEREG*LARGE & No relationship & $5.516^{* *}$ & 2.430 & + & -0.484 & 2.581 \\
\hline GOE & + & -0.231 & 0.382 & $?$ & 0.111 & 0.352 \\
\hline COMMISSION & + & 1.078 & 0.760 & $?$ & 0.014 & 0.685 \\
\hline ECON & $?$ & $-4.377 * * *$ & 0.695 & $?$ & 0.352 & 0.721 \\
\hline YIELD & - & $-3.773 * * *$ & 0.551 & $?$ & $1.260 * *$ & 0.522 \\
\hline SPECIALIZATION & + & 0.087 & 0.353 & $?$ & -0.036 & 0.195 \\
\hline LIFE & $?$ & 10.314 & 8.497 & $?$ & -2.886 & 6.395 \\
\hline-2 Log Likelihood & & 1324.3 & & & 1288.8 & \\
\hline
\end{tabular}

* Statistical significance at 0.10 level.

**Statistical significance at 0.05 level.

***Statistical significance at 0.01 level. 


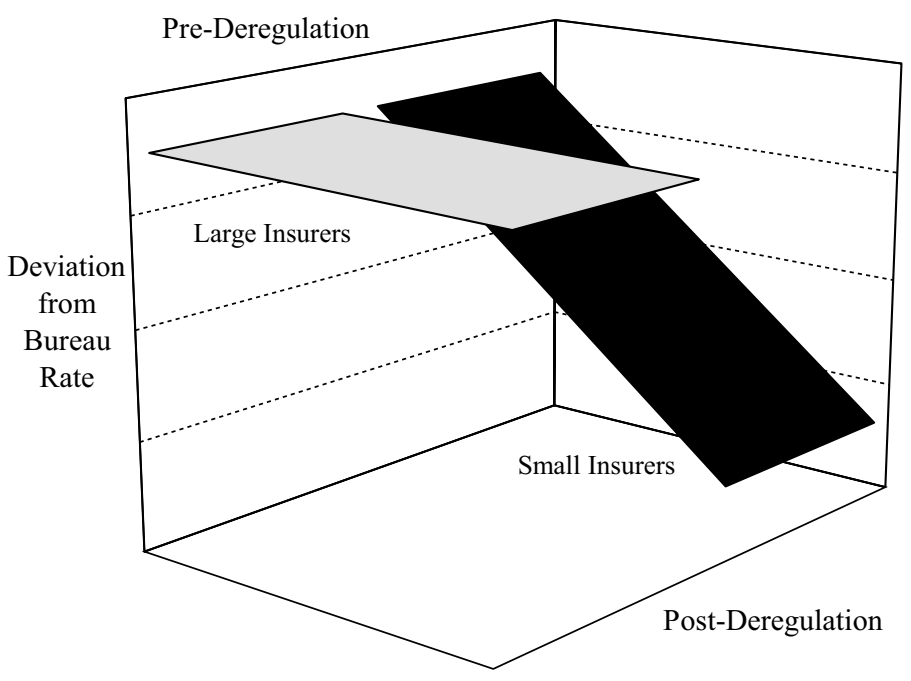

Figure 1. Changes in insurer pricing strategies: the cartel model.

role of this variable in the model was to merely control for variation in demand and supply of insurance services in the marketplace. One hypothesized implication would be that when the economy is relatively stronger, insurers feel less of a need to deviate from bureau rates, that is, less need to compete on price. The remaining control variables: COMMISSION, GOE, SPECIALIZATION, and LIFE, were not found to be statistically significant.

\section{Conclusion}

This paper examined the relationship shared by regulatory environment and insurer pricing strategies in the recently deregulated Japanese auto insurance marketplace. We found that insurer-pricing behaviour has changed subsequent to deregulation and the nature of those changes imply that the Japanese regulatory environment is now operating in a manner similar to Danzon's theorized cartel model (see Table 1 for a summary of the characteristics of the cartel model). Two primary empirical findings support this conclusion:

- Small firms displayed a greater willingness to compete on price while larger firms more closely adhered to bureau rates.

- While the magnitude of deviation differed, both large and small insurer groups deviated from bureau rates only in a downward (negative) direction.

\footnotetext{
${ }^{34}$ Netting the coefficients for the DEREG and DEREG*LARGE variables in the empirical results reveals the degree of change in pricing strategy of large insurers. The results suggest that large insurers increased their negative deviation from bureau rates subsequent to deregulation by 0.111 per cent.
} 
This analysis was the first of its kind to control for market regulation, price and nonprice behaviour - a feature not possible in the U.S. market. While a deeper understanding of pricing behaviour in the Japanese insurance market is significant inand-of-itself, these findings also have broader implications. A number of other national markets have recently moved from (or are presently in the process of moving from) highly regulated markets to more competitive systems, for example, China, India, some members of the European Union. To the extent the experience of the Japanese market reflects those of other national markets, policy makers and competitors alike should have a special interest in the short-term competitive dynamics revealed in this research.

Much work remains to be done related to the pricing behaviour of insurers in recently deregulated markets throughout the world. However, due to the recentness of deregulation in many national markets, only a limited number of years of data are presently available. Therefore, as these new regulatory environments mature, a periodic review of these same issues in those markets is warranted so that the veracity of earlier findings might be either supported, modified, or discredited based on future market behaviour.

\section{References}

Ancipink, P. (1980) 'Auto insurance in Massachusetts: A no-exit maze', Best's Review, Property-Liability 81(3): 28-32.

Barros, P. (1996) 'Competition Effects of Price Liberalization in Insurance', Journal of Industrial Economics 44(3): 267-287.

Beenstock, M., Dickinson, G. and Khajuria, S. (1988) 'The relationship between property-liability insurance premiums and income: An international analysis', Journal of Risk and Insurance 55: 259-272.

Browne, M., Chung, J.W. and Frees, E. (2000) 'International property-liability insurance consumption', Journal of Risk and Insurance 67: 73-90.

Conning and Company (1992) Regulatory Survey of the Property Casualty Industry, Hartford, CT: Conning and Company.

Cummins, J.D., Phillips, R. and Tennyson, S. (2001) 'Regulation, political influence and the price of automobile insurance', Journal of Insurance Regulation 20(1): 9-50.

Danzon, P. (1983) 'Rating bureaus in the U.S. property liability insurance markets: Anti or procompetitive?' Geneva Papers on Risk and Insurance 8(4): 371-402.

Eastman, K. and Maroney, P. (2000) 'Regulatory action on rate filings: The effect of recent legislative changes in Florida', Journal of Insurance Regulation 18(4): 527-550.

Finsinger, J. and Schmid, F. (1994) 'Prices, Distribution Channels and Regulatory Intervention in European Insurance Markets', The Geneva Papers on Risk and Insurance - Issues and Practices 19(70): 22-36.

Frech, H. and Samprone, J. (1980) 'The welfare loss of excess nonprice competition: The case of propertyliability insurance regulation', Journal of Law and Economics 23(2): 429-440.

General Accounting Office (GAO) (1979) Issues and Needed Improvements in State Regulation of the Insurance Business, Washington, DC: U.S. General Accounting Office.

Grace, M., Klein, R. and Phillips, R. (1998) 'Auto insurance reform: Salvation in South Carolina', in D. Bradford (ed.) The Economics of Property-Casualty Insurance, Chicago, IL: University of Chicago Press.

Greene, W.H. (1997) Econometric Analysis, 3rd edn, New York: MacMillan.

Hanson, J., Dineen, R. and Johnson, M. (1974) Monitoring Competition: A Means of Regulating the Property Liability Insurance Business, supplement to the 1974 NAIC Proceedings.

Harrington, S.E. (1984) 'The impact of rate regulation on prices and underwriting results in the propertyliability industry: A survey', Journal of Risk and Insurance 51: 577-623.

Hartman, G. (1970) 'Insurance experience and rating laws,', Journal of Risk and Insurance 37: 203-224. 
Hayakawa, H., Fischbeck, P. and Fischhoff, B. (2000) 'The Japanese automobile insurance industry: Regulation and market structure', Journal of Insurance Regulation 18(2): 385-403.

Ippolito, R. (1979) 'The Effects of Price Regulation in the Automobile Insurance Industry', Journal of Law and Economics 22(1): 55-89.

Jaffee, D. and Russell, T. (1998) 'The causes and consequences of rate regulation in the auto insurance industry', in D. Bradford (ed.) The Economics of Property-Casualty Insurance, Chicago, IL: University of Chicago Press.

Japan Non-Life Insurance Newsletter (1997) New Year's Address by the Chairman of the Association, January No. 43, Tokyo: The Marine and Fire Insurance Association of Japan, Inc.

Jeng, V. and Lai, G. (2005) 'Ownership structure, agency costs, specialization and efficiency: Analysis of Keiretsu and independent insurers in the Japanese non-life industry', Journal of Risk and Insurance forthcoming.

Joskow, P. (1973) 'Cartels, competition and regulation in the property-liability insurance industry', Bell Journal of Economics and Management Science 4(2): 375-427.

Kreps, D. and Scheinkman, J. (1983) 'Quantity precommitment and Bertrand competition yield cournot outcomes', Bell Journal of Economics 14: 326-337.

Kwon, W.J. and Skipper, H. (1997) 'Regulatory changes in the Japanese insurance market,', Journal of Insurance Regulation 16(2): 151-169.

Mintel, J. (1983) Insurance Rate Litigation, Boston, MA: Kluwer-Nijhoff.

Ma, Y. and Pope, N. (2003) 'Determinants of international insurers' participation in foreign non-life market', Journal of Risk and Insurance 70: 235-248.

Moody's Investor Services (1998) Industry Outlook: Japanese Property \& Casualty Insurance, October, Tokyo: Moody's Insurance Research.

Moody's Investor Services (1999) Industry Outlook: Japanese Property \& Casualty Insurance, December, Tokyo: Moody's Insurance Research.

Moody's Investor Services (2001) Industry Outlook: Japanese Property \& Casualty Insurance, January, Tokyo: Moody's Insurance Research.

Muir, J. (1968) 'Effects of legislation and regulation on insurance rates, filings, policies, underwriting', Best's Fire and Casualty News 68(2): 10.

Nadel, M. (1982) 'Auto insurance: The irrelevance of regulation', Regulation 6(Mar/Apr): 37-42.

Nanto, D. (1995) Deregulation as Market Opening in Japan Congressional Research Service Report, 95-224 E.

New York Insurance Department (1975) Cartels vs. Competition: A Critique of Insurance Price Regulation, New York: New York Insurance Department.

Nikkei Weekly (2001, May 7) 'Nonlife Insurers See Profits Tumble in Price Competition', Internet, available fromhttp://www.nni.nikkei.co.jp/AC/TNW/Search/Nni20010507MQ7T6FIN.htm;accessed 4 December 2001.

Ostrom, D. (1998) 'From colossus to casualty: The transformation of Japan's insurance industry', Japan Economic Institute Report No. 2A January 16.

Peltzman, S. (1976) 'Toward a more general theory of regulation', Journal of Law and Economics 19(2): 211-240.

Pope, N. (2004) 'Deregulation in the Japanese insurance marketplace: Sizzle or fizzle?' Journal of Insurance Regulation 22(3): 19-38.

Saba, R. (1978) 'An alternative theory of regulation of automobile insurance', Southern Economic Journal 44(2): 469-476.

Samprone, J. (1979) 'Rate regulation and nonprice competition in the property and liability insurance industry', Journal of Risk and Insurance 46: 683-696.

Schader, C. (1982) 'Rating services and the small company', in N. Weber (ed.) Insurance Deregulation: Issues and Perspectives, New York: The Conference Board.

Sonnenholzner, M. and Wambach, A. (2004) 'Oligopoly in insurance markets', in J. Teugels and B. Sundt (eds.) Encyclopedia of Actuarial Science, New Jersey: John Wiley \& Sons.

Stigler, G.J. (1968) 'Price and non-price competition', Journal of Political Economy 76(1): 149-154.

Stigler, G.J. (1971) 'The theory of economic regulation', Bell Journal of Economics and Management Science 2(1): 3-21. 
326

Swiss Re (2001) 'Profitability of the non-life insurance industry: it's back-to-basics time', Sigma No. 5, Zurich: Swiss Re.

Tennyson, S. (1997) 'The impact of rate regulation on state automobile insurance markets', Journal of Insurance Regulation 15(4): 502-523.

\section{About the Authors}

Nat Pope is an affiliated faculty at Bradley University, USA.

Yu-Luen Ma is an Assistant Professor of Insurance at Illinois State University, USA. 